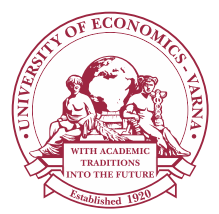

Izvestiya Journal of Varna University of Economics 3 (2021)

IZVES T I YA

Journal of Varna University of Economics

http://journal.ue-varna.bg

\title{
EMPIRICAL RESEARCH ON THE RELATIONSHIP BETWEEN CONSUMER ATTITUDES AND VALUES TOWARDS ADVERTISEMENTS BY MOBILE OPERATORS
}

\author{
Lyubomira SPASOVA ${ }^{1}$
}

${ }^{1}$ Department of Social Sciences and Business Language Training, Trakia University, Stara Zagora,
Bulgaria, E-mail: liubomira1975@abv.bg

JEL: M37

\begin{abstract}
The purpose of this article is to present research on consumer attitudes to mobile operator advertising, as well as their relationship with components of the value of consumers of mobile products and services. The Petty and Cacioppo's Elaboration Likelihood Model of Persuasion, which examines the variability of attitudes toward advertising, as well as the Schwartz method for changing values, are applied. The obtained results clearly show the presence of a relationship between the studied indicators, as well as behavioral changes in the individual target groups. The leading summary is that females aged 21 to 24 are more strongly influenced by advertising of mobile operators and the same target group shows higher values for establishing benevolence towards different family members and universalism as shows tolerance to the needs of representatives of individual social groups.
\end{abstract}

Key words:

persuasive influence, cognitive and affective attitudes, behavioral changes

(C) 2021 University of Economics - Varna

Citation: SPASOVA, Lyubomira (2021) Empirical Research on the Relationship between Consumer Attitudes and Values towards Advertisements by Mobile Operators. Izvestiya Journal of Varna University of Economics, 65 (3), pp. $277-293$.

DOI: $10.36997 / \mathrm{IJUEV} 2021.65 .3 .277$

\section{INTRODUCTION}

Human attitudes and pre-attitudes play a leading role in the process of persuasions' formation, looking for their connection with the impact on consumers, as well as the behavioral changes resulting from this impact. For the purposes of this study, some changes regarding the value system of young people are explained according to the 
Schwartz methodology for changing the values of the younger generation. The aim of the study is to establish some patterns in the formation of consumer attitudes and components of the value system of young people living in the cities of Sofia, Plovdiv and Stara Zagora.

The relevance of the theoretical need of the presented research is due to the fact that one of the most contested communications is advertising due to its characteristics. In addition to the specified theoretical parameters, the concepts "attitudes", "per-attitudes", "cognitive correspondence", "system of attitudes" and others should be analyzed. The considered analysis focuses on the socio-psychological, age and existential aspects of the value system of young people, but does not aim to study and establish all the main components of the value system. The conceptual apparatus of the present study also includes two bipolar deviations from the value system of the individual: selftranscendence - includes universalism and benevolence and self-affirmation - unites achievement and power. The research selection of organizations is also not accidental, because mobile companies in Bulgaria are one of the powerful advertisers which try to influence through advertising very aggressively. The main research goal is not only to prove the existence of advertising influence, but how it manages to determine changes in consumer attitudes, persuasions and behavior.

\section{CONSUMER ATTITUDES}

The attitudes that the communicator (in this case a mobile operator) can build are also perceived as an evaluative attitude, as it contains a positive or negative reaction to a certain stimulus. In the most general sense, attitudes are defined as the tendency to react in a certain way to certain questions or events or "a relatively stable habit, inner focus, or predisposition of a person to a certain type of reaction, which determines actions and experiences and can be interpreted as an intermediary between the stimulus and the response" (Hiebsch and Vorwerg, 1979, p.678). According to Hiebsch and Vorwerg, who study attitudes about social psychology, attitudes are „readiness to react, necessary and mandatory for certain groups in specific situations, which as a socio psychological category is the orientation of the individual determined by group norms" (Hiebsch and Vorwerg, 1979, p.675). Therefore, the formation of attitudes takes place in a particular social environment and is a reflection of its connections with the outside world. They are activated without conscious initiation in early childhood as ,striving to meet basic needs" (Hiebsch and Vorwerg, 1979, p.675) and learning new things, and the connection with the social environment is not broken. In the interaction between information and behavior, some cognitive structures are observed first, and then emotional ones follow. In psychology, they are known as cognitive, conative and emotional attitudes, which 
determine the readiness to respond to a particular situation. In psychology researchers seek the „cognitive correspondence“ (Eagly, 1890, p.34) between what people do and what they believe. Social psychologists like Eagly find that people are not so consistent in their behavior and for various reasons it (behavior) does not always correspond to their attitudes. The researchers" explanation is that the social environment and personal characteristics have a strong influence, which can prevent people from expressing their attitudes freely.

The classic model of forming attitudes in the mind of the recipient is the relationship between the stimulus for the realization of an idea and the reaction caused by the stimulation. In the process of persuasive communication, it is established that with repeated repetitions of the presentation of an idea, service or product, associative connections are created with the organization that caused the stimulus and desires for ownership to arise. This desire, in turn, is associated with the formation of a positive emotional attitude, which would completely predispose the recipient to the object of advertising. Along with the emotion, there is also the knowledge that shapes the cognitive attitude (Anderson, R., 1990, p.45) of the advertised object, which creates different ideas - conscious and unconscious, in the mind of the recipient, who at a certain stage of external influence could react, i.e. make a purchase. In this case, we again come to the concept of ,system of attitudes“.

Crespi uses the term „system of attitudes“ for what other authors call attitudes. He believes that the system of attitudes consists of four components: evaluation frameworks for comparison (values and interests); cognitive abilities (knowledge and beliefs); attachment (feelings); volitional actions (behavioral intentions) (Crespi, 1998, pp.87-89). According to the views of this researcher, the connection between attitude and value can be sought as part of the cognitive abilities of the individual. Cognitive attitudes (Anderson, R., 1990, p. 45) are based on knowledge of an object (brand, product, country of origin, service, etc.). With the help of this knowledge, consumers compare the positive and negative features of the promoted product, comparing both with analogues and in terms of their own needs and desires, and then give an objective assessment of the product. The notion that consumer attitudes, respectively a system of attitudes, determine consumer behavior, makes them extremely important for the formation of research on the persuasive influence of advertising. In this line of thought it becomes clear that the influence of the already formed attitude in the perception and processing of information is not limited to selectivity, but also covers the interpretation of already perceived information. The more complex process is related to overcoming the perceived negative attitude, which in turn can be achieved by creating the right advertising concept for proper influence. It should not be forgotten, however, that attitudes are hypothetical constructs that psychologists invented to explain phenomena 
of interest. As Gordon Allport put it seven decades ago, "How does one know that attitudes exist at all? Only by necessary inference. There must be something to account for the consistency of conduct" (Allport, 1935, p. 836)

The measurement of the attitudes of a target group, as well as components of the value system of young people, is not done only to differentiate the audience and all its characteristics, but to change the attitudes if necessary. Last but not least, ways are sought for the formation of positive values as a result of established positive conative, cognitive and affective attitudes. This creates a favorable prerequisite for stimulating the desired behavior - making a purchase. Before moving on to looking for ways to change attitudes, existing attitudes need to be identified. Three criteria are indicated here: Direction - whether the examined person approves or disapproves the specific product (positive or negative); Degree - refers to the value that the subject gives to the object, a specific scale; Importance - the importance that the researched person attaches to the respective object, towards which the attitude is formed. (Colley, 1960, p.347)

Other research questions arise such as: do all attitudes show the same tendency to change; which attitudes are more lasting and how can they be changed? KroeberReil divides the attitudes into several groups, which show significant differences in the relationship with behavior. The task of changing the attitude stems from the existing relationship between attitude and behavior, so the author identifies the following types: specific and non-specific attitudes; attitudes formed through experience and formed through communication; stable and unstable. „Attitudes formed as a result of direct experience with an object have a much stronger influence on behavior than attitudes formed as a result of communication." (Kroebel-Riel, 1990, pp.60-69) The same author believes that the attitudes measured today show tomorrow's behavior, but he does not take into account the fact that the stability of attitudes can only be said for a certain period of time. The preservation of the stability of the attitude depends on whether it is leading for the person or not, just like the use of a certain product or service characterizes the values of the person.

\section{CONSUMER VALUE SYSTEM}

For the purposes of this study, a secondary analysis is made of the individual values of the target groups - young people aged 18 to 25 years, because they are an important determinant of human behavior and consumer attitudes. In addition, researchers have found a link between attitudes and values as part of a person's cognitive abilities. (Festinger, 1957, pp.117-140)

There are 11 value types, identified and developed according to the Schwartz model, which include several main value categories, each category and subcategory 
combining values with the same motivational purpose. (Schwartz, 1990, p.878-891) There are several approaches in the experimental study of values: M. Rokeach's structural-energy approach is based on the ranking method. (Rokeach, 1973, p.123) According to a number of psychologists, they are closely related to the self-concept and psychosocial identity of the individual. The structural-content approach is based on a content analysis of the value hierarchy both on a social and individual level for example in Hofstede and Schwartz. In this second approach, the most common is the Schwartz method, which analyzes the values in terms of their motivational content. This makes the model appropriate for the present study, applying Schwartz's methodology for changing values in the younger generation. The considered types form two bipolar deviations: self-transcendence - includes universalism and benevolence; self-affirmation - unites achievement and authority. The two varieties oppose the values that emphasize the acceptance of others as equals and care for their well-being, the values of personal success and dominance over others.

Another important deviation that is directly relevant to the present study is openness to change (self-direction, hedonism and stimulation) versus conservatism (tradition, security and conformity) as opposed to values emphasizing independent thought and action, as well as the desire for change, the values of self-restraint, maintaining tradition and stability. (Schwartz, 2007, pp. 648-650) Therefore, the analysis of values shows that self-direction in Bulgarian youth is an individual value that is tied to the postmodern values of the global world. The difference in the concepts: „value" and „motive" should be taken into account, as well as the fact that "they belong to a more general value-motivational sphere of the personality". (Taneva, T., 2001, p. 19). Here there is a predominance of the values of personal self-expression (such as choice, independence of thought and action, not limited by external imposed boundaries) over the values of personal self-preservation. In terms of value interests, the comparative analysis of the data from $\mathrm{M}$. Garvanova's research reveals that the openness to change retains its first place, followed in second place by self-transcendence. "Hedonism is placed in the forefront by the students that are studied in 2006-2007" (Garvanova, 2013, pp.45-56). Therefore, for more modern students, the values associated with the delivery of pleasure and enjoyment of life become increasingly important as a priority. It should not be forgotten that in the value profile of various respondents, in which automaticity and activity are in leading positions, there is a more pronounced confidence among men to turn the potential into reality. (Taneva, T., 2009, p. 196). Therefore, respondents are expected to be more willing to buy mobile products and services at risk.

The considered analysis focuses on the socio-psychological, age and existential aspects of the value system of young people, but does not aim to study and establish all the main components of the value system. Young people in Bulgaria are representatives 
of the modern and pro-Western value orientation in our country, but in part of the study period researchers found a lack of interest in the modern and new, which shows a crisis in the value system of the young generation.

\section{PURPOSE AND TASKS OF THE RESEARCH}

The lack of research on consumer attitudes and pre-attitudes, as well as the establishment of their relationship with components of the value system of young people, is the main reason for conducting such research. The main tasks of the conducted research are the following:

- To monitor the changes and the stability of the built consumer attitudes;

- To indicate some of the manifested components of the value system of young people when using mobile products and services;

- To look for the connection between attitude and value in young people aged 18 to 25 .

Based on the proposed theoretical framework, the following hypotheses are made:

$\mathrm{H}_{0}$ - Consumer attitudes of young people using mobile products and services under the influence of advertising cannot form some of the components of their value system, as well as motivate certain consumer behavior.

$\mathrm{H}_{1}$ - The consumer attitudes of young people using mobile products and services can form some of the components of their value system, as well as stimulate certain consumer behavior.

\section{DATA ANALYSIS}

The analysis for this study is based on 300 respondents, on the principle of respondents aged 18 to 25 years. Among them, $57.5 \%$ (113 participants) were male respondents and $42.5 \%$ (187 participants) female respondents. The only requirement for the respondents is to have used or use products and services of mobile operators in Bulgaria. In the first stage of the research according to Petty and Cacioppo's method a first questionnaire is applied, which takes into account the attitudes and pre-attitudes of young people, the initial reactions of the subjects, which require in-depth thinking in the perception of advertising messages. The author places a different number of items (statements), measuring the strong and weak arguments of the advertisement, which determine the end result of persuasion, as well as the manifestation of the cognitive, affective and conative attitudes of the respondents. The aim is to determine which part of the respective advertisement carries information (cognition) and which satisfaction (hedonism). The average values of the responses of each subject are used to measure 
the pre-communication attitudes (Petty and Cacioppo, 1986, p.26).

The experimental design is intra-group because all subjects go through the same conditions. When determining the age, there are three groups: the first group is from 18 to 20 years $-43 \%$, the second group from 21 to 24 years $-42.7 \%$ and the third group over 25 years $-14 \%$. Regarding their affiliation to a mobile operator, the respondents are in the following groups: Telenor subscribers - 121 people or $40 \%$, then A1 - 88 people or $29 \%$, Vivacom are 75 people or $25 \%$, and another, other than indicated we have 2 respondents or $1 \%$. An option for data entry is also included - a subscriber of more than one mobile operator, for which there are 14 or 5\%. (Spasova, 2019, p.838846). This article presents some of the results of a larger author's study of consumer attitudes. Additional research is being done on the gender of the respondents, which as an independent variable is directly dependent on age and the final purchase decision. Interesting results on the influence of gender on risky behavior are presented by Sander and McCrmick, who compare the types of risk that men or women prefer. The authors found that, in general, representatives of both sexes identify financial and emotional risks as the least preferred, especially by men (Tanev, T., 2009, p.194). Women are significantly more likely than men to take emotional and relationship risks. At the same time, in general, in self-reports people overestimate their ability to take risks (Tanev, T., 2009p. 195).

\section{LIMITATIONS OF STUDIES}

The considered analysis focuses on the socio-psychological, age and existential aspects of the value system of young people, but does not aim to study and establish all the main components of the value system. The proposed study identifies the following limitations:

- Its period covers the time from 2018 to 2020 (years in which the three mobile operators are present on the market), during which the advertising activity of the organizations can be monitored and analyzed, as well as to establish the indicated dependencies between consumer attitudes and values categories that determine consumer behavior.

- The number of respondents is limited: 300 respondents were interviewed on the principle of respondents who gave their consent to be interviewed. Not all advertising methods and models are available for consideration. The aim is rather to mark those that explain the relationships between attitude and value.

- Not all communication activities of mobile operators are considered, but only advertising as part of persuasive communication that changes consumer behavior.

- The respondents are regionally limited in Bulgaria, i.e. the respondents are 
students at Sofia, Plovdiv and Trakia universities, single people and students - 93\%.

- No data is provided regarding the gender of the surveyed persons for establishing new dependencies with the dependent variables - attitudes, pre-attitudes and beliefs, leading to a certain extreme behavior.

\section{RELIABILITY ANALYSIS}

To check the reliability of factors, internal consistency coefficients (Cronbach's Alpha) were assessed. The reliability scores in this research were: Perception of advertising (positive statements) (0.673), Advertising perception behavior, (0.746), Positive emotions under the influence of advertising (0.646), Reasons for purchase (0.770), Impact through socially significant causes $(0.860)$. It shows all the variables have the Alpha value in the 'acceptable' range (George and Mallery, 2003).

The more important results of the conducted one-factor analysis (ANOVA) of variance with an independent variable - ,mobile operator“ and a dependent variable - ,attitudes and pre-attitudes" are the following: which mobile operator the surveyed respondents belong to, most of them have a neutral pre-attitude towards the mobile operator with whom they establish a relationship or this is $44 \%$ of the respondents. We should not underestimate the fact that $31.7 \%$ are those who have positive attitudes towards their mobile operator, which speaks of an initial positive opinion and higher expectations from young consumers. The most important result is the increase in the percentages of negative attitudes from pre-attitudes to current attitudes from $17.3 \%$ to $26.3 \%$, which is evidence of a decline in trust after the use of products and services of mobile operators in Bulgaria. $\mathrm{R}^{2}=0.331$ which means the independent variables „mobile operator" express the dependable variable ,attitudes and pre-attitudes“ $31.1 \%$. The reasons for the change of attitudes are examined with the question: If there is a change in your attitudes to it, state one of the following reasons for change, in which one-factor analysis shows that the main reasons for changing attitudes are the following: Offers sufficient benefits for customers, Offers innovative ideas for customers, with a Cronbach's alpha reliability factor of 0.647 .

In order to take into account the real impact of the advertisement, as well as to make a purchase after an observed advertisement of a mobile operator, the respondents are asked the question: Do you use products and services of mobile operators after observing their advertisements? Out of a total of 163 respondents who give either a positive answer or an answer to some extent, the largest percentage of Telenor subscribers made a purchase after an observed advertisement - 59 people surveyed.

In the study of the persuasive impact of advertising, it is necessary to indicate those components of advertising communication through which a real impact on young 
people has been achieved. To achieve this goal, respondents are tasked to evaluate the advertisements of a mobile operator to which they were subscribers before, during and after the impact. 15 items are proposed, the first two with good reliability. The first factor - Perception of advertising (positive statements) is composed of items: They are interesting; I always liked them; They are funny, where the answers are strongly and negatively colored with the other items. The reliability of this factor increases with the presence of the item - I always liked them, from 0.578 to 0.673 according to Cronbach's Alpha.

During this stage aimed at studying the degree of accessibility of attitudes, the Petty and Cacioppo's model of the highest probability of persuasion was used. To identify the peripheral signals that change the temporarily unstable attitudes, the impact is both centrally and peripherally, the question arises: How do you read / listen / watch the ads of mobile operators that reach you? Five factors are formed in it, but only the fifth is with good reliability. The factor is - Advertising perception behavior, as its reliability increases when removing "I never listen to mobile advertisements" from 0.691 to 0.746 according to Cronbach's Alpha.

Some positive emotions under the influence of advertising have also been studied with the factor - Positive emotions under the influence of advertising, of which there is a relatively good reliability as Cronbach's Alpha is up to 0.646. With the highest average values is the first item - „Did you feel satisfied with the advertising of a mobile operator?" which indicates that the advertisement is fun, almost similar to the results for the last item, which seeks satisfaction with the impact of advertising. But it should not be forgotten that here the values of the positive answers are between 1 with an answer never and 2 - with an answer sometimes from 1.75 to 1.90, as they stand far from 3 with an answer always, which shows that the respondents think that the advertisement to some extent it has a positive effect, but not very strongly. Therefore, building positive emotions, and hence attitudes through advertising, is difficult for the mobile operator.

In order to establish the reasons for the purchase, the respondents answered the question: What makes you make a purchase with this mobile operator? Because of the factor: Reasons for purchase includes all statements except the item (statement): „Offering profitable products and services", it has a value of 0.770 according to Cronbach"s Alpha, i.e. it is considered "acceptable". This question examines consumer behavior after an impact. The question includes 8 items that guide young respondents to the respective behavior. There are some items in this question, such as: The pleasure of owning something new; The feeling of being like other young people, which aims to explore the incentives for young people's behavior. Another important item is the following: The advantages of the advertised products and services, which takes into account the role of the impact of advertising. It will be compared with items from 
other questions to establish dependencies on the impact, attitudes and behavior of young respondents. The presented diagram shows that the highest value has the item: Package services-2.87, and in second place in terms of values is the item: Professional service-2.68, (the values are close to the answer yes - 3), which is a clear indicator for motivating the active behavior of the young respondent by offering favorable conditions and good service.



Fig. 1. Average values of the reasons for making a purchase by the mobile operator

In order to study the values expressing striving for understanding, tolerance and preservation of well-being, social justice, environmental protection, summarized in the name universalism, a study is made through the following question: "Which of the specific activities of your chosen mobile operator related to advertising would you like?". This is a component that can be verified as part of the corporate social responsibility of the mobile operator such as: providing funds for the treatment of people, for orphans, for the elderly, for sick animals, funds for environmental protection. Two factors have been formed, the first - Impact through socially significant causes includes 6 of the 8 statements: „Provision of funds for treatment of people“, „Provision of funds for orphans", „Provision of funds for the elderly", „Provision of funds for sick animals "“Construction of housing for homeless people“ and „Environmental protection activities" with a reliability indicator of 0.860 , which is considered to be completely satisfactory according to Cronbach's Alpha.

The diagram shows the average values of the items, where the largest share has the activities for environmental protection-3.34, and in second place is the provision of funds for the elderly-2.23. In the third place, the respondents put the provision of funds for orphans, the values of which are 2.00. The influence of these activities in 
combination with advertising media is an important part of the study because they are accurate evidence of one of the components of the value system - universalism, which proves the understanding and tolerance that are not lost in the use of more material goods. This component is directly related to the component of benevolence, i.e. values aimed at preserving and maintaining the well-being of people with whom we often have personal contacts: responsiveness, devotion, generosity, honesty, responsibility, true friendship, devoted love. The benevolence of the individual is checked with the question: Are you willing to help your relative or friend by buying a mobile phone or paying for a mobile service in your chosen mobile operator? where respondents indicate their propensity for this act. The tendency of the targeted persons to make a purchase for their relative or friend has been established, the presence or absence of one of the values - benevolence - is examined. This value belongs to the group of values aimed at preserving and maintaining the well-being of people with whom we often have personal contacts: responsiveness, devotion, generosity, honesty, responsibility, true friendship, devoted love. The results show that only $39 \%$ of the respondents or 117 respondents are fully prepared to help a relative or friend by buying a product from a mobile operator. $45 \%$ or 136 respondents gave an answer - sometimes, which to some extent includes a positive answer. This can be explained by several reasons: either there are circumstances that sometimes deter respondents from performing this noble act, or there is a moment of distraction after the impact of advertising.

\section{Which of the specific activities of the mobile operator of your choice, related to advertising, would you like:}

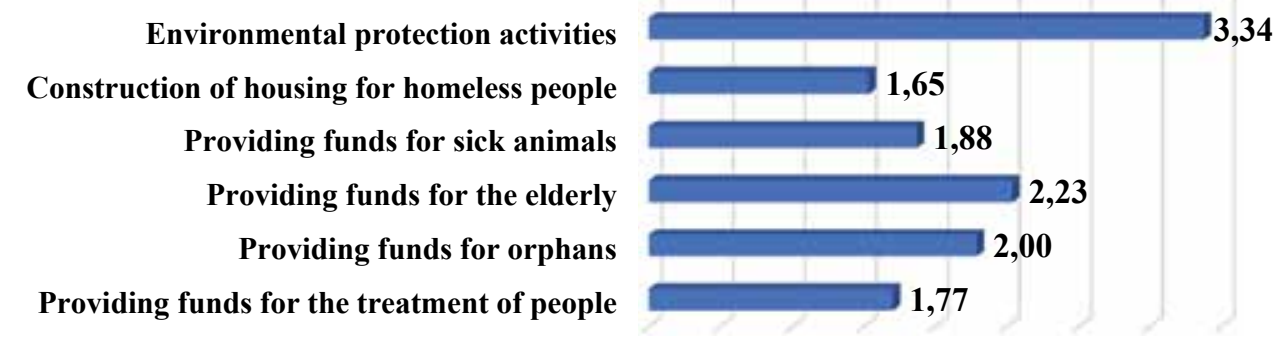

Fig. 2. Influence of Corporate social responsibility on mobile companies

The obtained result allows to make the following summary: the possession of a mobile product or service can, as well as the realization of accessible and successful mobile communication, suggested through advertising, can activate values contained 
in the factor: Reasons for purchase. Therefore, benevolence among young people is an individual value that influences their consumer behavior. The current modern world offers many more products and services that make a connection between real values in life and material possessions. All these components present in advertising communication can affect the target groups and achieve a real effect. In order to establish the identified dependencies, some correlation analyzes will be conducted, through which the connection between perceptions, emotions and behavior is sought, which helps the manifestation of certain consumer attitudes and categories of values.

\section{CORRELATION ANALYSES BETWEEN THE INFLUENCING FACTORS}

To investigate the linear relationship between the formed scales, Pearson's correlation analysis of the formed factors was performed. Pearson's simple correlation coefficient provides a numerical estimate of both the strength of the linear relationship and the direction. The results of the first test show a moderate statistically significant positive correlation between the scales of the two formed opposite factors - Perception of advertising of a mobile operator (positive statements) and Positive emotions after influence of advertising $(r=0.457 ; p<0.01)$. This means that high values on one scale tend to correspond to high values on the other. When comparing the statements falling on the two scales - Perception of advertising of a mobile operator (positive statements) with the following items: „They are interesting", "They are fun" and the reversible statement „They are annoying and monotonous", where the values are reversed, so that consent to this statement should be subtracted from the overall score on the scale and Positive emotions after influence of advertising with the following items: „Did you feel satisfied with the ads of a mobile operator", „Did you feel excited about the ads of a mobile operator", „Did you feel you are enthusiastic about mobile operator advertisements', it is easy to conclude that the positive correlation can be explained by the positive evaluation of the advertisements. Since the attitudes of the respondents are positive towards the advertisements of the mobile operators, it is quite possible that after the interaction with them the respondents experience positive, satisfying emotions. Therefore, the positive affective attitudes of the respondents can lead to the perception of their products and services.

The results of the second correlation show a moderate statistically significant positive correlation between the scales of the two formed opposite factors: Reasons for more attention and Positive feeling after helping a loved one, where $(r=0.354$; $\mathrm{p}<0.01$ ), therefore high values on one scale correspond to high values on the other. When comparing the statements falling into the two scales - Reasons for more attention 
Lyubomira Spasova. Empirical Research on the Relationship

between Consumer Attitudes and Values towards Advertisements by Mobile Operators

with the following items: „When there are lower prices“, „,When there are elements of attractiveness of the products", „When the exact product / service is named", „When product demonstrations „"“ When advertising is combined with other media products (TV show, film, news, on the Internet)" and Positive feeling after helping a loved one with the following items: "I felt happy ," "I felt satisfied , aims to identify the reasons for greater attention on the part of the respondents, as well as their relationship with the emotional attitudes of young people providing impartial assistance to a loved one. The impact is again through advertising, therefore it is done centrally and peripherally. Therefore, with a greater commitment of attention from young people, it would lead to a change in behavior and to an increase in the level of benevolence in them, and hence to positive emotions after helping a loved one.

To establish the reasons for the manifestation of benevolence in young people, an additional correlation analysis is conducted between two formed factors. The results show a moderate statistically significant positive correlation between the scales of the two formed opposite factors: Reasons for making a purchase at a mobile operator and Positive feeling after helping a relative or friend, where $(r=0.333 ; p<0.01)$. This means that high values on one scale tend to correspond to high values on the other. When comparing the statements fall into the two scales - Reasons for making a purchase at a mobile operator with the items: „Package services", „Professional service“, „Fast communication", „Advantages of the advertised products and services", „Modern offers", "The pleasure to own something new", and Positive feeling after helping a relative or friend with the items: "I felt happy", ,I felt satisfied", it is established that after making a purchase with a mobile operator chosen by the respondent, as well as the provision of impartial assistance to a loved one creates a sense of satisfaction in young people. This shows that the benevolence component belonging to the value system of young people is not exhausted. High values in the act of purchase indicate higher values of positive feelings in respondents. The high degree of satisfaction among young respondents when buying a product or service for a loved one, as well as increasing the values of the one-factor analysis by Crombach's Alpha from 0.346 to 0.412 when adding the items: I felt useful; and This aroused noble feelings in me, is proof of the presence of benevolence in them. In addition, this value is manifested in a situation of personal sales, when the mobile operator is professional in offering bundled services, professional service and fast communication. Therefore, the impact of a company's advertising can be enhanced in the presence of triggering events (helping a loved one) and the presence of influential components of advertising in personal sales.

According to Table 1, the ratio (R) of Positive emotions after influence of advertising and Perception of advertising of a mobile operator (positive statements) is 0.457, and with Positive feeling after helping a relative or friend is 0.449 . This shows 
a significant positive relationship between the independent variables, finding that the perception of a mobile operator's advertisement, as well as the positive feelings after the help of a relative or friend, can create more positive emotions in young respondents. From the obtained data it is clear that positive feelings after the help of a loved one can also increase the reasons for attention in young people $-\mathrm{R}=0.607$. In order to study the behavior of the respondents, additional statistical procedures were performed, which found that the increase in the engagement of the respondents, i.e. making a purchase, is directly related to the positive feelings of young people after the help of a relative.

\section{RESULTS AND DISCUSSION}

According to the results, it is clear that hypothesis „, $\mathrm{H}_{0}$ - Consumer attitudes of young people using mobile products and services under the influence of advertising cannot form some of the components of their value system, as well as motivate certain consumer behavior" is rejected because the results show a connection between the consumer attitudes of the respondents and their value system. One-factor analysis of variance shows that despite the increase in negative attitudes after using the products of the respective companies, young people perceive the perception of their advertisements. This is most strongly reported by Telenor subscribers. The high reliability of the obtained one-factor analyzes of behavior after the perception of advertising by a mobile operator also proves that young people aged 18 to 25 feel satisfied with a purchase. This conclusion is supported by the result on the reasons for making a purchase. Correlation analyzes show that with the increase of positive emotions, their greater perception among young people grows, and this also affects their benevolence towards other members of society. The conclusion made shows that it can be said with confidence that there is a connection between the consumer attitudes of the respondents and some of the components of their value system such as benevolence and universalism. The adoption and approval of activities related to the Corporate Social Responsibility of Youth is in support of, $\mathrm{H}_{0}$ - Consumer attitudes of young people using mobile products and services can form some of the components of their value system, as well as stimulate certain consumer behavior ". What makes it difficult for the researcher is the complete evidence for this connection, but the conducted primary and secondary analyzes indicate the existence of such a connection. This article presents some of the results of a larger study on consumer attitudes, beliefs and components of the value system of young people, which is to be continued in order to identify trends in the respondents. It is extremely important to prove major deviations regarding the relationship between attitude and value as part of human behavior. 


\section{CONCLUSION}

The study of consumer attitudes, human beliefs and the values of young people under the influence of advertising is an extremely complex process and the main reason is their variability. According to leading psychological and sociological studies, some tendencies are established among the individual targeted groups, such as a change in pre-attitudes and attitudes, which is expressed in an increase in negative to positive attitudes. This is the problem that all companies have to deal with, striving to build a positive image in the minds of consumers about the company itself and its products. This is achieved by conducting some activities related to Corporate Social Responsibility, which in turn lead to the creation of understanding and tolerance by young people to other social groups. Thus is formed one of the leading values - universalism, which has not lost its value in the use of more products and services. In addition, the present study attempts to prove the relationship between the attitudes of young consumers and some of the components of their value system, finding that the presence of positive affective and cognitive attitudes in young respondents is a valid reason for buying close person. Therefore, the establishment of positive affective attitudes is directly dependent on another component of the value system of consumers - benevolence, which is contrary to the value of self-direction, i.e. values that express a desire for independence of thought and action. These components require more in-depth research to establish all the main links between attitudes, pre-attitudes, persuasions and values that would affect the overall behavior of young consumers in Bulgaria.

\section{REFERENCES}

1. Anderson, J. R., (1990). Cognitive psychology and its implications, $3^{\text {rd }}$ ed. New York: Freeman, 1990.

2. Allport, G. W. (1935). Attitudes. In C. Murchison (Ed.), A handbook of social psychology. Worcester, MA: Clark University Press, 1935.

3. Bachinska, K., and Garvanova, M., (2012). Gender differences in the value system - individual and socio-cultural influences. Sofia: IK, Kolibri, 2012.

4. Brazinskaitė M., Ramanauskaite A. (2011). The development of long-term relationship between mobile service organizations and consumers. Global Academic Society Journal: Social Science Insight, Vol. 4, No. 12, pp. 26-36. ISSN 2029-0365.

5. Dilova, M., and Nikova, G., et al., (1989). Dictionary of Psychology. Sofia: NI, 1989.

6. Doganov, D., Durankev, B., and Katrandjiev, H., (2003). Sofia: Integrated Marketing Communications. IM, 2003. 
7. Dowling, G. (2000). Creating corporate reputation - identity, image, presentation. Sofia: ROI Communication, 2000.

8. Colley, R.H. (1960). Defining advertising goals and measuring advertising results. $2^{\text {nd }}$ Ed. New York: ARA, 1960.

9. Crespi, I., (1998). The Public Opinion Process. How the people speak. New York: $1^{\text {st }}$ edition, 1998.

10. Eagly, H., (1890). Uneven progress: Social psychology and the study of attitudes. Journal of personality and social psychology, Vol. 63: pp.3-12.

11. Eagly, A. H., and Chaiken, S. (1993). The psychology of attitudes. Fort Worth, TX: Harcourt Brace, 1993.

12. Festinger, L., (1957). A theory of cognitive dissonance. Evanston IL: Row, Peterson, 1957.

13. Festinger, L., and Carsmimith, J. M. (1959). Cognitive consequences of forced compliance. Journal of Abnormal and Social Psychology, Vol.58, ,1959, p. 113-120.

14. Festinger, L., Riecken, H.W., and Schachter, S., (1956). When prophecy fails. Minneapolis: University of Minnesota Press, 1956.

15. Ganeva, Z., (2009). Conceptions of the transition to adulthood among emerging adults in Bulgaria. In J. C. McDermott, A. Kington, \& M. Matultsikova (Eds.), Paradigms and research of educational practice (pp. 249-262). Los Angeles, CA, USA: Department of Education, Antioch University, 2009.

16. Garvanova, M., (2011). Basic life aims, satisfaction with life and value crisis at Bulgarian students (comparative approach). Bulgarian Journal of Psychology, Vol. 41 (3-4), pp. 77-84.

17. Garvanova, M., (2013). Transformation in the values of contemporary Bulgarian. Sofia, Bulgaria: "For the letters - pismenehy", 2013.

18. Garvanova, M., (2016). Dynamics in the collective orientations of students in the condition of value crisis in Bulgaria. Psychological Thought, Vol. 99(1), pp.104122.

19. George, D. and Mallery, P., (2003). SPSS for Windows step by step: A simple guide and reference. Allyn \& Bacon, Boston, 2003.

20. Hiebsch, H. and Vorwerg, M., (1979). Sozialpsychologie. Berlin: Gruppe, 1979.

21. Kroebel-Riel, W., (1990). Konsumentenverhalten, Sofia, ed. Munich, 1990.

22. Kovacheva, V. Chantov, I. Pehlivanov, and S. Devkova (Eds.), (1999). Proceedings of the State University of Library Studies and Information Technologies, Sofia, Bulgaria: "For the letters - O pismenehy", Vol. 12, pp. 275-289.

23. Lord, Ross, Lepper, (1976)., Biased assimilation and attitude polarization: The effects of prior theories on subsequently considered evidence“, Journal of Personality 
and Social Psychology, Vol. 37, pp. 2098-3109.

24. Petrova, A., (1999). Psychology of Advertising, Sofia: published by ForCom, 1999.

25. Rokeach, M., (1973). The Nature of Human Values. Free Press, New York, 1973.

26. Schwartz, S.H., and Bilsky, W. (1990). Toward a theory of the universal content and structure of values: extensions and cross-cultural replications, Journal of Personality and Social Psychology, Vol. 58(5): 878-891, 1990.

27. Schwartz, S. H., Sagiv, L., and Antonovsky, A., (1991). The stability and social desirability of value priorities. Israel: Hebrew University of Jerusalem. Submitted for publication, 1991.

28. Schwartz, N., (2007). Attitude Construction: Evaluation in Context, Journal of Social Cognition, Vol 25, No. 5, 2007, pp.638-656.

29. Spasova, L., and Gundasheva, Zh., (2019). Psychological Models for Attitudes and Persuasion Changes in Consumer Behavior, Trakia Journal of Sciences, Vol. 17, Suppl. 1, pp 838-846.

30. Taneva T. (2005) Citation: Value parameters of pedagogical work of teachers of special schools, Pedagog - jednej czy wielu drog, №3, Akademi podlaskiej. 67 (2), pp. 81-95.

31. Taneva, T., P. Angelova (2000) Citation: A place of education and qualification in the value system of entrepreneurship in our country, collection. Pedagogicalpsychological and medical-anthropological problems of the personality, Thracian University, St. Zagora, pp.177-180.

32. Taneva, T. (2009) Subjective perception of economic risk, 2009, Stara Zagora, p.21.

33. Petty, R., and Cacioppo, J., (1986). Communication and persuasion: the central and peripheral routes to attitude change. New York: Spring-Verlag, 1986.

34. Petty, R. E., and Cacioppo, J. T. (1979). Issue involvement can increase or decrease persuasion by enhancing message-relevant cognitive responses. Journal of Personality and Social Psychology, Vol. 37: 1915-26.

35. Petty, R. E., and Cacioppo, J. T. (1986). The elaboration likelihood model of persuasion. In Advances in Experimental Social Psychology, vol. 19, L. Berkowitz, N.Y: Academic Press, pp. 125-162p 1986.

36. Rokeach, M., (1973). The Nature of Human Values. New York: Free Press, 1973. 